\title{
Analysis Tool for Passive Optical Access Network
}

\author{
P. Pinho ${ }^{1,2} \oplus^{\oplus}$, D. Camacho ${ }^{1}$ \\ ${ }^{1}$ Instituto Superior de Engenharia de Lisboa, Lisboa, Portugal \\ ${ }^{2}$ Instituto de Telecomunicações, Aveiro, Portugal \\ pedro.pinho@isel.pt,A41841@alunos.isel.pt
}

\begin{abstract}
Fiber optic access networks have been considered a definitive solution to the constant need for increasingly higher bandwidths. For this reason, PON (Passive Optical Network) have grown enormously in the recent years, offering different solutions to the end customer, whether it is residential or business. However, the PON project is complex and a time-consuming process. This paper is focused on a tool design that, when combined with the schematic of the PON project, performs the survey of all equipment used in the projected cell. This tool provides also the attenuation calculations, as well as the techno-economic study of the network. Simulations were carried out to test the viability of the software, considering the network analysis in two cases: with one service provider using the network or with two service providers sharing it.

Index Terms - PON, GPON, Optic Fiber, Access Network, Techno-Economic Analysis.
\end{abstract}

\section{INTRODUCTION}

We currently live in an interconnected world, in which telecommunications shorten distances between continents and people. A world where the major challenge for service providers is to guarantee the greatest possible bandwidth for the largest number of users, with different terminals and services.

The installation of optical fiber in the access network, to provide adequate bandwidth and quality of service for the different services, is an expensive process. While the consumer demand for bandwidth continues to grow, solutions for the development of access networks have been studied [1]. The FiberTo-The $x$ (FTTx) solution becomes the focus of Service Providers (SP) in the development of the network, aiming to bring the fiber as close as possible to customers and make the network compatible with future fiber optic technologies. [2] discusses the future direction of optical access networks and proposes a new optical access architecture that will support the evolution of optical access systems from a Fiber-To-The-Home (FFTH) infrastructure to a common optical access platform that connects various devices and systems to anywhere they want to reach.

The project of an optical fiber network, with the goal to increase the bandwidth, the transmission distance and the number of users, needs to take into account all the parameters associated with its implementation. Thus, the realization of an access network project becomes a complex process, which 
Journal of Microwaves, Optoelectronics and Electromagnetic Applications, Vol. 20, No. 2, June 2021 DOI: http://dx.doi.org/10.1590/2179-10742021v20i21185

slows down the optical fiber networks growing process.

Network planning is a critical issue for SP, especially in this globalization time and with intense competition. The current telecommunications market requires flexible and adaptable network planning methodologies, for future evolutions of network architectures. In addition, there will be a need for software tools to assist SP in their networks' development. Generally, this planning is done in AutoCAD software. However, it only assists in the design of the optic fiber network. Hence, it is required to process manually other important parameters, such as required components list, the attenuation calculations in order to verify if the project comply with the recommendations, and the budget for the project implementation.

In this context, there are multiple optical fiber network simulators that try to reproduce an accurate analysis of all the important parameters. 3-GIS [3] is a network planning and management tool, which analyzes specific network variables. This software provides: market evaluation of a demanded and approved service point in the region, material costs, construction costs, construction documents for the licensing process, identification of broken fibers and the management of signal levels.

Hawkeye Computing [4] is a management, planning and design tool for telecommunications infrastructures. This application works with optical fiber, coaxial cable and copper pairs networks. This software provides: identification of the potential number of customers in the project area, cost calculation, required components list, project documentation, project information for contractors and suppliers, maintenance and troubleshooting and operational management of the active network.

ITS-Fiber Engineer [5] is a set of software used for the implementation of fiber optic projects. This software performs: contract and material management, cost calculation, more efficient user grouping algorithm for placing Optical Distribution Points (ODP) or visiting points, export the final project to AutoCAD (dwg file) and Excel.

NetTerrain OSP [6] is a telecommunications network management software. Some of the characteristics are the following: physical and logical models of the network, equipment connection mapping, conduct mapping, identification of problems in capacity management.

VETRO FiberMap [7] is a tool for planning and managing fiber optic networks. This software performs: calculation of costs in the project of the network, evaluation of expected revenue scenarios, automatic network design, equipment connection mapping. The previous tools [3-7] are paid and there was no information regarding the development of this kind of tools for PON networks. Moreover, these types of tools are very complex, uses several inputs and different telecommunication systems and its implementation could not be intuitive or trivial.

The main contribution of this paper consists on developing a simulation application for PON networks. It is intended that this application performs the dimensioning and the techno-economic analysis of this type of network for different scenarios of projects developed in AutoCAD. Thus, it is possible to do an analysis in a scenario where there are two SP sharing the same infrastructure. 
This application was developed in MATLAB to complement the AutoCAD design tool. With this application it is possible to analyse the dimensioned networks, through the reading of the AutoCAD files. Furthermore, it is possible to calculate the loss budget for every client, identify the required components list and estimate the values involved in the implementation of the network. This latter feature provides the techno-economic analysis of the dimensioned network, in order to understand the impact of one or two SP in the global investment.

The remaining of this paper is organized as follows. Section II presents a new structure to read AutoCAD file projects of a PON and details the software's analysis and the algorithm used in different scenarios. Section III presents the input arguments for the simulation process and discusses the obtained results from the tool. Finally, Section IV enumerates the main conclusions of the paper.

\section{ACCESS Network SimUlator}

In order to be able to associate a telecommunication network's project developed in AutoCAD, to the proposed tool, it will be necessary to introduce a new structure in the AutoCAD file. The presented solution consists in the introduction of names, attributes and labels in AutoCAD blocks. With this approach it is possible to obtain all the information required to analyze the complete PON design and obtain the techno-economic study of the network.

\section{A. Suggested Structure}

For the extracted file to be readable in the software tool, it is necessary to add attributes to all the blocks in the AutoCAD project. For the fusion point (JFO) there will be two attributes, the JFO ID, and location. For the splitting point (JSO) there is only one attribute, its ID. For the building there are seven attributes: the number of residential customers, the number of commercial customers, the assigned distribution point ID, the number of floors, the number of fractions, the building ID, and finally a flag to consider, or not, the installation of telecommunications infrastructure inside the building. For the distribution point there are two attributes: the ID and the location.

Since in AutoCAD the representation of fiber cables is done using polylines, it will not be possible to assign attributes to them. Therefore, it was decided to add a label, thus making it possible to assign attributes to the fiber cables. Therefore, fiber cables will have nine attributes: the destination equipment, the source equipment, the quantity of cable fibers, the dimension in meters of the aerial cable, the dimension in meters of the duct cable, the dimension in meters of the building's front cable and the quantity of transitions between different optical cables locations, which can be performed by air, on the building's front and or in the underground.

\section{B. Implemented Algorithm}

As we can see from Figure 2, the results tab in the software shows the required components list, the loss budget, the location of the splitters and the financial forecast for the next 4 years.

In the required components list, all the material in CO (Central Office) is considered, but not the ones from the OLT (Optical Line Terminal). In the OSP (OutSide Plant) construction, it is considered 
the lengths of each type of fiber cables, the number of installed optical distributed points, the splitters in JSOs and their distribution points, the number of metallic tube risers, etc. In the ISP (Inside Plant) construction, it is considered the optical distribution point's modules (primary and secondary), the lengths of the cables installed in the vertical column, the number of floorboxes, etc.

To calculate the loss budget, Figure 1, can also be used as a support to understand the network's attenuations. According to [8], the total attenuation of the path is given by equation (1), where $L_{T}$ is the total attenuation, $\alpha$ is the fiber attenuation coefficient, $L$ is the fiber length, $L_{C}$ is the attenuation of the connectors, $L_{\mathrm{M}}$ is the attenuation of the multiplexer, $L_{\mathrm{F}}$ is the attenuation of fiber's fusions and $L_{S}$ is the splitters' attenuation.

$=++M+F+$

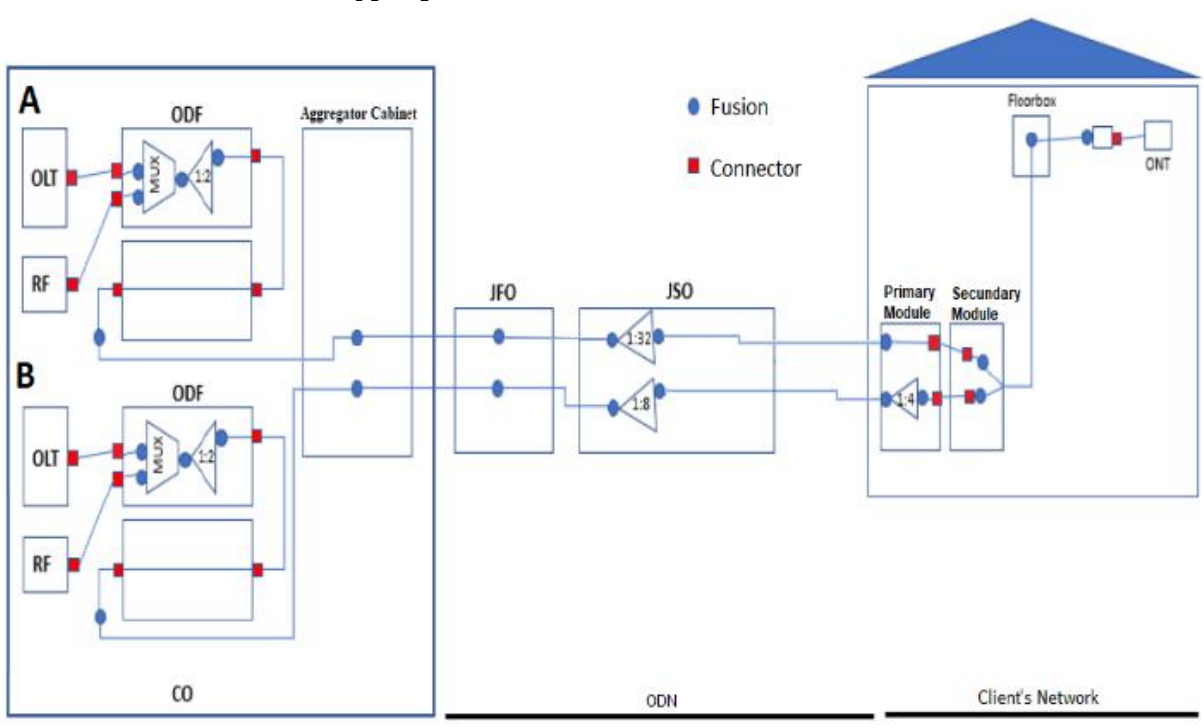

Fig. 1. Attenuation components [7]
(1)

Figure 1 represents an example of a link between two SP (A and B), that share the same access network, and a final client. In order to calculate the total path attenuation of a connection, it is required to count every component, starting from the OLT to ONT (see Figure 1). In CO, and by default, it is always considered five connectors and five fusions, due to the MUX and splitter present in ODF (Optical Distribution Frame). In the ODN (Optical Distribution Network), it is considered the length of the fiber, one fusion for each JFO and two fusions for each JSO found in the path, as seen in Figure 1. In ISP, it is always considered the worst case, this being the client located on the top floor of the building. For that, it is considered the fiber length, three connectors and the number of fusions, depending if there is a splitter or a floorbox present inside the ISP construction.

The attenuation values are given in Table I, where the splitters' attenuation values are given by the maximum insertion losses given in [10]. 


\begin{tabular}{cc} 
Table I. Attenuation Values $[10]$ \\
\hline Component & Attenuation \\
\hline Cable & $0,4 \mathrm{~dB} / \mathrm{km}$ \\
Connector & $0,3 \mathrm{~dB}$ \\
Fusion & $0,05 \mathrm{~dB}$ \\
MUX & $1,5 \mathrm{~dB}$ \\
$1: 2$ & $3,8 \mathrm{~dB}$ \\
$1: 4$ & $7,5 \mathrm{~dB}$ \\
$1: 8$ & $10,6 \mathrm{~dB}$ \\
$1: 16$ & $13,8 \mathrm{~dB}$ \\
$1: 32$ & $17,0 \mathrm{~dB}$ \\
\hline
\end{tabular}

Regarding the number of splitters present in the splitting points, with the help of labels created in AutoCAD, it is possible to calculate the total number of splitters in the network's, splitting points and distribution points.

As for the economic part of the network, the total network price is calculated, according to the material used and the cost of licenses. The break even point is, by definition, the temporal point where the total income equals to the total invested, in this case, in months. In the scenario of two SP sharing the infrastructure, the total cost of the network will be divided by the two and the break even point is half the total cost of the network, assuming that the SP share the network's cost. The total net income is calculated for the first 4 years of the net.

The percentage of FTTH users is given as the ratio between FTTH users, with the ODP located inside the building's facilities, and FTTB (Fiber to the Building) users, with the distribution point located in the building's facilities [11]. In the techno-economic study of the network, CAPEX (Capital Expenditure) defines the cost of all equipment types and its installation for the network construction [12]. In our study, we consider the CAPEX cost, rather than the OPEX (Operational Expenditure) cost. The OPEX defines the cost of renting any type of network infrastructure or equipment, and the network's maintenance.

\section{Simulation Results}

Technical-economic analysis of a telecommunication's network is essential for the SP. In this concrete case, the main objective is to design a fiber optic network to provide broadband telecommunications services in the area of Lisbon city, in Portugal. The simulated cell is composed by 2113 users, being 1925 residential and 188 commercial [9].

\section{A. Input arguments for one $S P$}

Figure 2 illustrates the graphical interface of the software tool and the obtained results for one SP. As it can be seen, the software's output displays data, such as the network required component list for its implementation, the network cost for each SP, the number of months until a SP pays the investment, the number of FTTH clients and the economic forecasts for the next four years. 


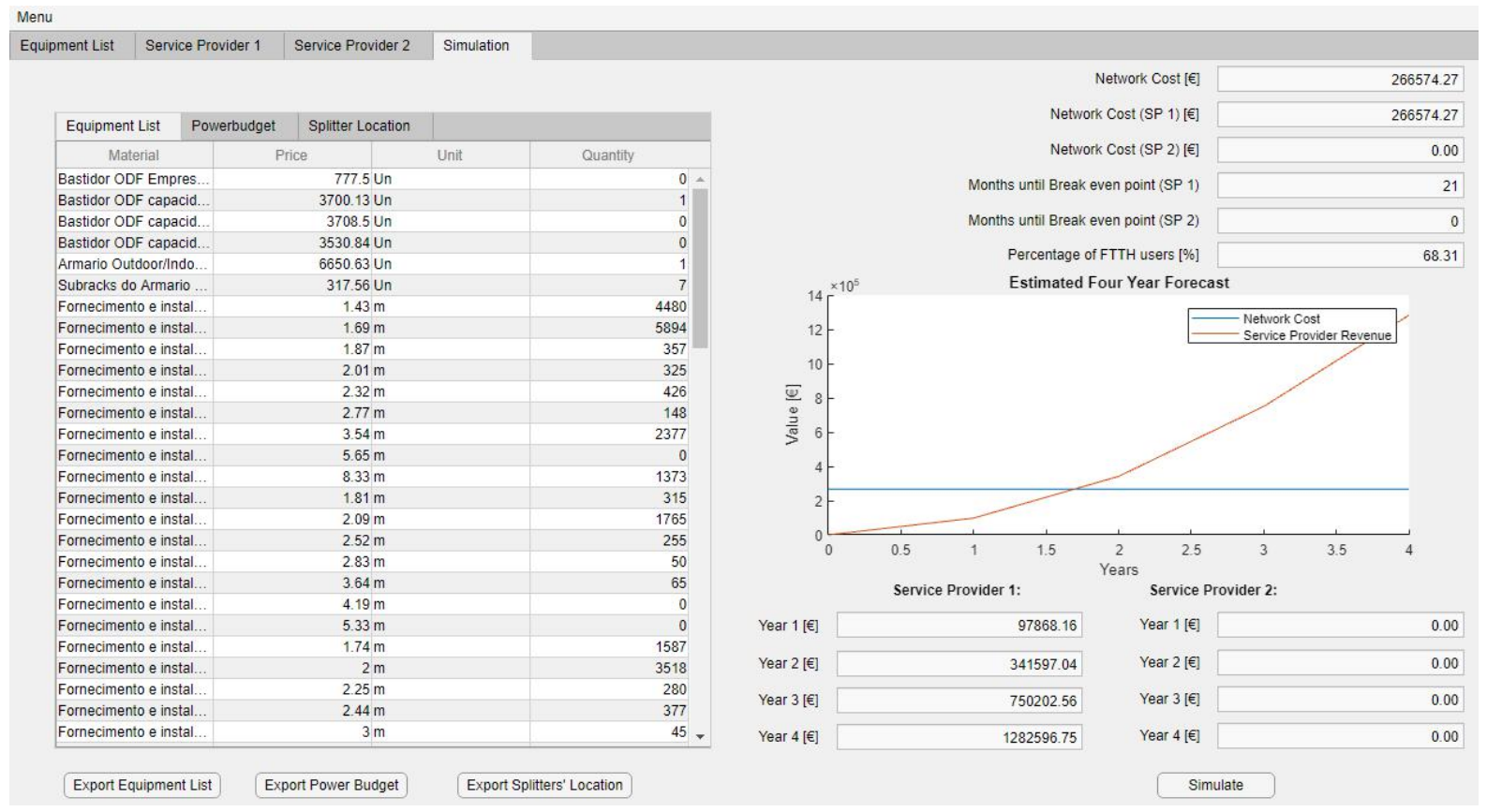

Fig. 2. Graphical User Interface.

A simulation was carried out for this cell, for one SP, considering a $70 \%$ of penetration rate for the telecommunication's services. Table II represents an example of monthly fees for different service plans, delivered by a SP and its penetration rates for the covered customers.

TABle II. Simulated Plan’s Details

\begin{tabular}{cccccc}
\hline Plan & Monthly payment & Year 1 [\%] & Year 2 [\%] & Year 3 [\%] & Year 4 [\%] \\
\hline R1 & $29,00 €$ & 16 & 31 & 33 & 53 \\
R2 & $57,00 €$ & 4 & 11 & 31 & 28 \\
R3 & $71,00 €$ & 2 & 6 & 4 & 8 \\
R4 & $100,00 €$ & 0,3 & 2 & 6 & 10 \\
C5 & $600,00 €$ & 1 & 2 & 3 & 4 \\
\hline
\end{tabular}

The penetration percentages of a plan are referring to the number of customers that are covered by the $70 \%$ of the network's coverage. It is concluded that, after four years, $98.88 \%$ of the residential customers covered by the network will subscribe to the services offered by the SP. It is important to note that other values could be used and the conclusion can change with different options.

\section{B. Analysis of obtained simulated results for one $S P$}

The required components list represents the survey of all the materials necessary for the developed network, that is, all the components that make up the network from the CO, ODN, and the ISP network. For the material price, the used table is available at [13]. Using the developed tool, the total cost of the network will be $266.574,27 €$. In this amount is not considered the cost of active equipment to be installed in the CO (OLT and RF overlay), nor the cost of renting telecommunications infrastructures and the network maintenance, since these items are considered in OPEX. 
Figure 3 shows the network's financial forecast over four years after the network was implemented. Also, in the same figure it is possible to see the break-even point, and in this case will be one year and nine months after the network is active. Table III represents the network's performance over four years.

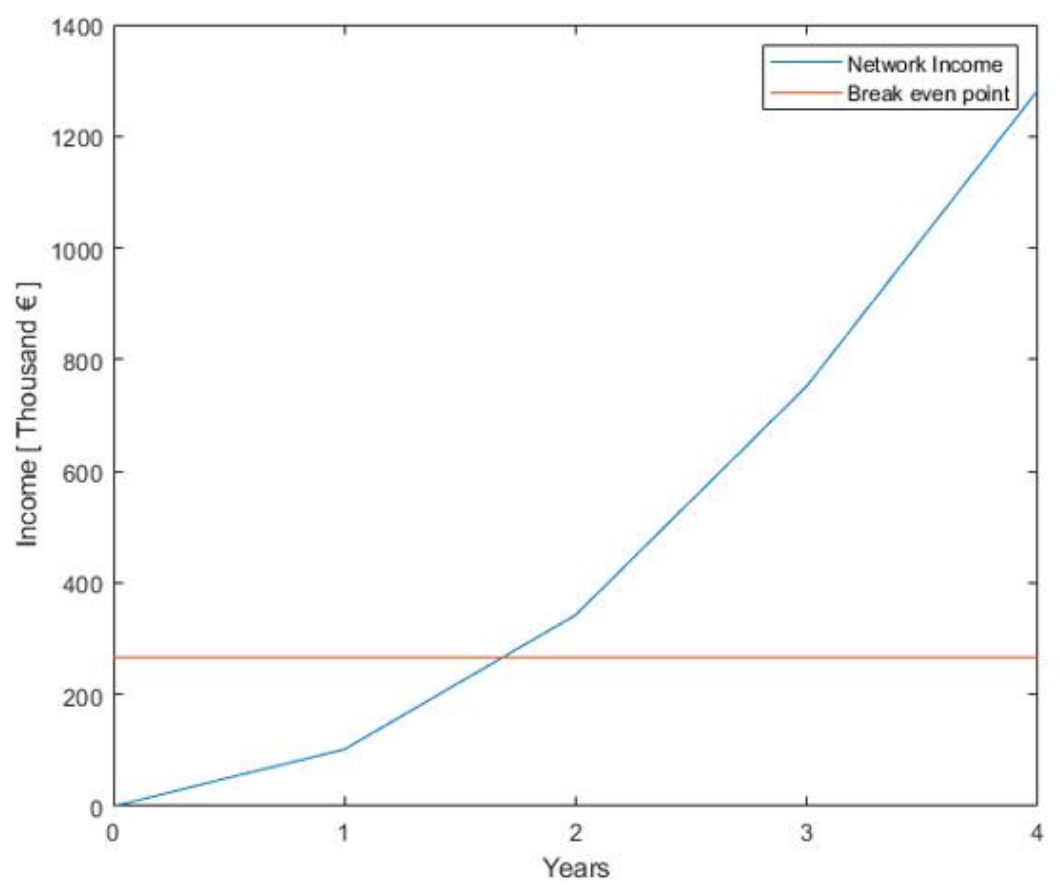

Fig. 3. Income forecast.

TABLE III. ANNUAL INCOME

\begin{tabular}{ccccc}
\hline Year & $\mathbf{1}$ & $\mathbf{2}$ & $\mathbf{3}$ & $\mathbf{4}$ \\
\hline Income [€] & $102.096,94$ & $342.593,11$ & $752.738,02$ & $1.282 .809,55$ \\
\hline
\end{tabular}

To support the construction of the network, there is a feature in the software that provides information about the location of all the splitters calculated in the network, in each JSO and ODP. Thus, Table IV represents the location of the splitters calculated in the network simulation.

TABLE IV. SPLITTER'S LOCATION OUTPUT

\begin{tabular}{cccccc}
\hline Location & $\mathbf{1 : 3 2}$ & $\mathbf{1 : 1 6}$ & $\mathbf{1 : 8}$ & $\mathbf{1 : 4}$ & $\mathbf{1 : 2}$ \\
\hline JSO08 & 6 & 1 & 1 & 0 & 0 \\
JSO06 & 6 & 0 & 0 & 0 & 0 \\
JSO05 & 7 & 1 & 0 & 0 & 0 \\
JSO10 & 8 & 1 & 0 & 1 & 0 \\
JSO01 & 7 & 1 & 0 & 0 & 0 \\
JSO04 & 7 & 1 & 1 & 1 & 0 \\
JSO03 & 4 & 1 & 1 & 1 & 0 \\
JSO09 & 4 & 1 & 0 & 0 & 0 \\
JSO11 & 1 & 1 & 0 & 0 & 0 \\
JSO07 & 4 & 1 & 0 & 0 & 0 \\
JSO02 & 9 & 0 & 0 & 0 & 0 \\
ODP0046 & 1 & 0 & 0 & 0 & 0 \\
ODP0032 & 0 & 0 & 1 & 1 & 0 \\
\hline
\end{tabular}


The optical power budget is the amount of power needed to successfully transmit signals from a distance, via fiber connection. Table $\mathrm{V}$ represents a portion of the computed path attenuations. Using this output will be possible to analyze if all connections are according to the standards.

TABLE V. LINK LOSS OUTPUT

\begin{tabular}{ccc}
\hline ID & ODP & Link Loss \\
\hline 11200123 & ODP0081 & 26,1961 \\
11200122 & ODP0096 & 26,2076 \\
11200121 & ODP0102 & 26,2191 \\
11200115 & ODP0115 & 26,3771 \\
11200114 & ODP0072 & 26,0984 \\
11200113 & ODP0084 & 26,1053 \\
11200112 & ODP0072 & 26,0984 \\
& & \\
$\vdots$ & $\vdots$ & $\vdots$ \\
11200111 & ODP0028 & 25,6087 \\
11200110 & ODP0031 & 25,5857 \\
11200109 & ODP0031 & 25,5857 \\
11200108 & ODP0031 & 25,5857 \\
\hline
\end{tabular}

Depending on the link loss values, the SP can choose which class of ONT (Optical Network Terminal) and OLT are used in the network [14]. When implementing an access network, the SP has to choose which class of active equipment will be used. For example, for the ODP which ID is 11200121 (see Table V), the class B + in ONT and OLT can be used, since class B + can handle a Power Budget up to $28 \mathrm{~dB}$ [14], [15]. The formula for power budget calculation [14], [16] is given by (1), where $\mathrm{P}_{\mathrm{B}}$ is the power budget, $\mathrm{P}_{\mathrm{T}}$ is the transmission power of the class $\mathrm{B}+, \mathrm{P}_{\mathrm{SENS}}$ is the ONT sensitivity and $\mathrm{L}_{\mathrm{T}}$ the total loss for the building with the ID 11200121. This equation can also be used for class checking and disregarding safety margins [16].

$$
\begin{gathered}
\mathrm{P}_{\mathrm{B}}=\left(\mathrm{P}_{\mathrm{T}}-\left(\mathrm{P}_{\mathrm{SENS}}\right)\right)-\mathrm{L}_{\mathrm{T}}>0, \\
\mathrm{P}_{\mathrm{B}}=(1.5-(-27))-27.1832>0,
\end{gathered}
$$

\section{Input arguments for two $S P$}

Figure 4 illustrates the graphical interface of the software tool and the obtained results for a network shared by two SP. As it can be seen, the software's output displays the same data as the previous simulation, but now for both SP. 


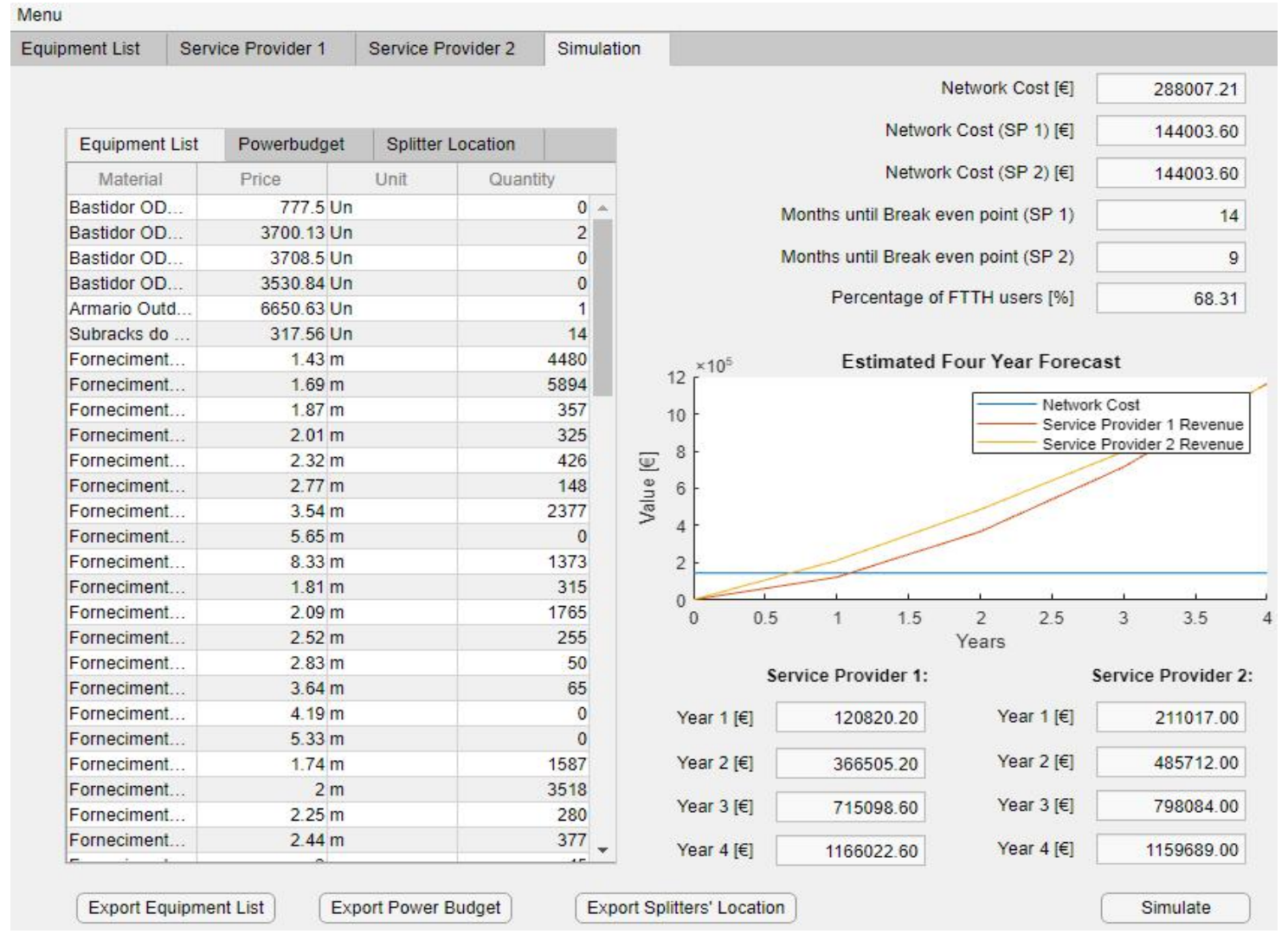

Fig. 4. Graphical User Interface.

A simulation was carried out for this cell, for two SP, considering a $100 \%$ of penetration rate for the telecommunication's services, being able to cover the whole cell. Table VI and VII represents an example of monthly fees for different service plans and its penetration rates for the covered customers, delivered by a SP 1 and SP 2, respectively.

TABle VI. Simulated Plan's Details fOR SP 1

\begin{tabular}{cccccc}
\hline Plan & Monthly payment & Year 1 [\%] & Year 2 [\%] & Year 3 [\%] & Year 4 [\%] \\
\hline R1 & $25,00 €$ & 13 & 25 & 39 & 60 \\
R2 & $60,00 €$ & 12 & 25 & 34 & 40 \\
C5 & $500,00 €$ & 1 & 2 & 3 & 4 \\
\hline
\end{tabular}

Table VII. Simulated Plan’s Details for SP 2

\begin{tabular}{cccccc}
\hline Plan & Monthly payment & Year 1 [\%] & Year 2 [\%] & Year 3 [\%] & Year 4 [\%] \\
\hline R1 & $20,00 €$ & 35 & 40 & 45 & 55 \\
R2 & $45,00 €$ & 25 & 35 & 40 & 45 \\
C5 & $500,00 €$ & 2 & 4 & 6 & 8 \\
\hline
\end{tabular}

\section{Analysis of obtained simulated Results for two SP}

As mentioned previously, the components list represents the survey of all the materials necessary for the developed network, that is, all the components that make up the network from the CO, ODN, and the ISP network. Using the developed tool, the total cost of the network is 288.007,21€ which 
will be shared by both SP 1 and SP 2. For the material price, the used table is available at [13]. In this amount is not considered the cost of active equipment to be installed in the CO (OLT and RF overlay), nor the cost of renting telecommunications infrastructures and the network maintenance, since these items are considered in OPEX.

Figure 5 shows the network's financial forecast over four years after the network was implemented for both SP. Also, in the same figure it is possible to see the break-even point for both SP. In this case, the break-even point will be reached one year and two months for SP 1 and 9 months for SP 2, after the network is active. Table VIII represents the network's performance over four years.

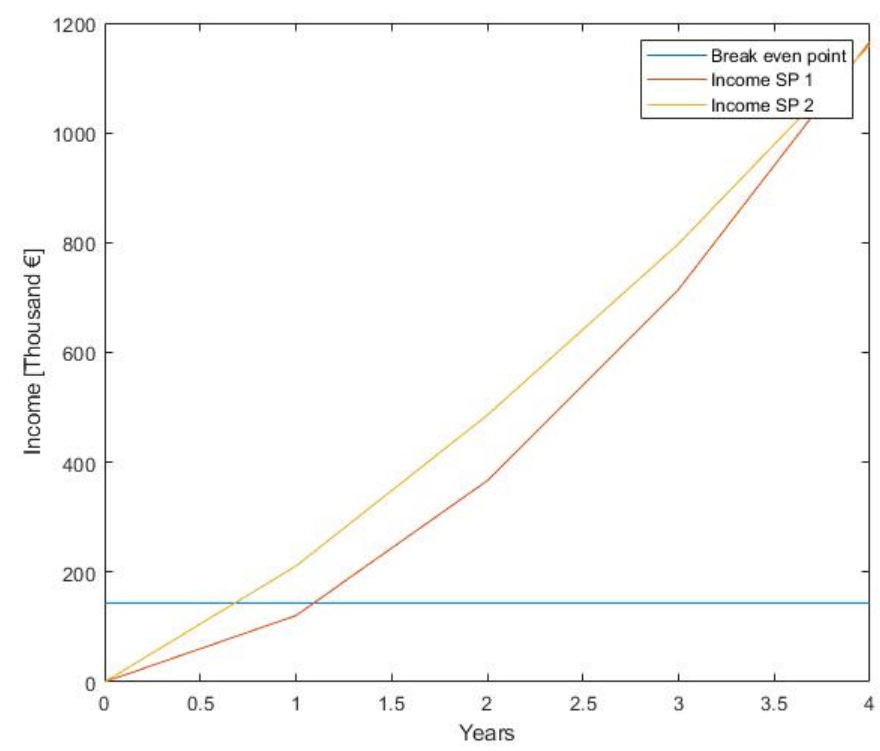

Fig. 5. Income forecast for two SP.

TABLE VIII. ANNUAL INCOME

\begin{tabular}{cccccc}
\hline Year & $\mathbf{1}$ & $\mathbf{2}$ & $\mathbf{3}$ & $\mathbf{4}$ \\
\hline Income SP 1 [€] & $120.820,20$ & $366.505,20$ & $715.098,60$ & $1.166 .022,60$ \\
\hline Income SP 2 [€] & $211.017,00$ & $485.712,00$ & $798.084,00$ & $1.159 .689,00$ \\
\hline
\end{tabular}

The cost of implementing a cell, being or not shared by two SP, ranges between $250.000 €$ and $300.000 €$, using the prices from the table found at [13].

Considering that both SP use the same network, the number of splitters in JSO will be the same, although will be added splitters inside the buildings to compensate the higher number of clients. Therefore, Table IX represents the splitters that were added in the builds and a portion of the computed path attenuations. As mentioned before, the introduction of new splitters in the network will cause higher loss. Using this output will be possible to analyze if all connections are according to the standards. For this example, and for the ODP0032, which ID is 11200106 (see Table IX), is 
the only ODP that is allowed to have services, if we consider the B+ class in both ONT and OLT [14], [15].

TABLE IX. SPLITTER's LOCATION AND LinK LOSS FOR SP 1 AND SP 2

\begin{tabular}{cccccccc}
\hline ID & Location & $\mathbf{1 : 3 2}$ & $\mathbf{1 : 1 6}$ & $\mathbf{1 : 8}$ & $\mathbf{1 : 4}$ & $\mathbf{1 : 2}$ & $\begin{array}{c}\text { Link } \\
\text { Loss }\end{array}$ \\
\hline 11200013 & ODP0122 & 0 & 0 & 0 & 1 & 0 & 30,3218 \\
11200032 & ODP0090 & 0 & 0 & 0 & 1 & 0 & 34,7472 \\
11300047 & ODP0006 & 0 & 0 & 1 & 0 & 0 & 34,6403 \\
$\vdots$ & $\vdots$ & $\vdots$ & $\vdots$ & & $\vdots$ & $\vdots$ & $\vdots$ \\
11200106 & ODP0032 & 0 & 0 & 0 & 0 & 0 & 25,5673
\end{tabular}

\section{CONCLUSIONS}

The techno-economic analysis of a simulated cell, in this case in Benfica - Lisbon, Portugal, depends on several factors, such as the cell size, the type of existing infrastructure, the access to conduits, the licenses ORAP and ORAC (Portuguese licenses to implement a network), the installed equipment types, the CAPEX and the OPEX. If the network is used by two SP, it is possible for one SP to rent the telecommunications infrastructure or both SPs can agree to share the cost of the network.

The projected cell, when simulated for one SP, had a cost of $266.574,27 €$. In the case of monthly fees, for example plan R1 (see Table II), it is a price well below any competitor, thus aiming to attract any potential customer. However, this also results in a significant reduction of income. On the other hand, a break even point would be reached in about a year after the network is deployed. At the end of four years, about $100 \%$ of potential customers are considered as customers of the SP and the network would yield 1.282.809,55€.

It can be concluded that, when dimensioning an access network, one of the most important points in a techno economic analysis is the network penetration rate. A SP, even with more expensive plans, but with a lower penetration rate, will take longer to reach a break even point. It is also important to take into account good practices in the access networks design. For example, a special care should be considered in the amount of fibers estimation for the network, in order to avoid the splitter usage, since they are the most important elements for the attenuation estimation.

\section{ACKNOWLEDGMENT}

This work is funded by FCT/MCTES through national funds and when applicable co-funded EU funds under the project UIDB/50008/2020-UIDP/50008/2020

\section{REFERENCES}

[1] P. Kourtessis et al. (2009) Evolution of Optical Access Networks. In: Tomkos I., Spyropoulou M., Ennser K., Köhn M., Mikac B. (eds) Towards Digital Optical Networks. Lecture Notes in Computer Science, vol 5412. Springer, Berlin, Heidelberg. https://doi.org/10.1007/978-3-642-01524-3_5

[2] J. Kani, J. Terada, T. Hatano, S. Kim, K. Asaka and T. Yamada, "Future optical access network enabled by modularization and softwarization of access and transmission functions" in IEEE/OSA Journal of Optical Communications and Networking, vol. 12, no. 9, pp. D48-D56, September 2020, doi: 10.1364/JOCN.391544. 
Journal of Microwaves, Optoelectronics and Electromagnetic Applications, Vol. 20, No. 2, June 2021 DOI: http://dx.doi.org/10.1590/2179-10742021v20i21185

[3] 3-GIS. (2021, Jan. 11). Fiber network management [Online]. Available: https://3-gis.com/fiber-network-planningmanagement-software-3-gis

[4] Hawkeye Computing. (2020, Jun. 20). Inside Planning [Online]. Available: https://hawkeye.se/inside-planning/

[5] ITS-Fiber Engineer. (2020, Jun. 20). FTTH design: ITS-Fiber Engineer [Online]. Available: https://www.itsimplicity.nl/design

[6] netTerrain OSP. (2020, Jun. 20). Outside Plant and Campus Connectivity [Online]. Available: https://graphicalnetworks.com/outside-plant/

[7] VETRO FiberMap. (2020, Jun. 21). Fiber Management: From Strategy to Splice [Online]. Available: https://www.vetrofibermap.com/

[8] N. Mubarakah, Soeharwinto and G. Nouvan, "Fiber Optic Trainer for Link Budget Measurement Tool in Optical Communication System," 2019 3rd International Conference on Electrical, Telecommunication and Computer Engineering (ELTICOM), Medan, Indonesia, pp. 44-47, 2019. doi: 10.1109/ELTICOM47379.2019.8943931.

[9] A. Oliveira, "Redes de Acesso em Fibra Ótica: Situação Atual e Evolução", Telecommunications Master's Thesis, Instituto superior de Engenharia de Lisboa, Lisboa, Portugal, 2017.

[10] Huawei. (2021, Jan. 2). Optical Power Loss and Budget [Online]. Available: https://support.huawei.com/huaweiconnect/carrier/en/thread-446053.html

[11] J. Park, G. Y. Kim, H. J. Park and J. H. Kim, "FTTH Deployment Status \& Strategy in Korea: GW-PON Based FTTH Field Trial and Reach Extension Strategy of FTTH in Korea," IEEE GLOBECOM 2008 - 2008 IEEE Global Telecommunications Conference, New Orleans, LO, pp. 1-3, 2008. doi: 10.1109/GLOCOM.2008.ECP.1074.

[12] Y. Li, N. Hua and X. Zheng, "An analysis of optimized CapEx for multi-core fiber based optical networks," 2014 13th International Conference on Optical Communications and Networks (ICOCN), Suzhou, pp. 1-4, 2014. doi: 10.1109/ICOCN.2014.6987071.

[13] D. Camacho, "Ferramenta para análise de implementação de redes de acesso", Telecommunications Master's Thesis, Instituto superior de Engenharia de Lisboa, Lisboa, Portugal, 2020.

[14] P. Pinho, Optical Communication Technology, Intech Open, Croatia, 2017

[15] G. Keiser, FTTX Concepts and applications, John Wiley \& Sons, Inc, 2006.

[16] C. Gonçalves, "GPON/FTTH: FTTH Fiber to the Home", Telecommunications Master's Thesis, Universidade da Madeira, Madeira, Portugal, 2009. 